\title{
Relationship Between Orthostatic Hypotension and Cognitive Functions in Multiple System Atrophy: A Longitudinal Study
}

\begin{abstract}
Sofia Cuoco, Immacolata Carotenuto, Arianna Cappiello, Sara Scannapieco, Maria Claudia Russillo, Valentina Andreozzi, Lorenzo Forino, Marianna Amboni, Marina Picillo, Roberto Erro, Paolo Barone and Maria Teresa Pellecchia*
\end{abstract}

Center for Neurodegenerative diseases (CEMAND), Department of Medicine, Surgery and Dentistry, Neuroscience section, University of Salerno, Salerno, Italy

Introduction: The aim of this study is to investigate the impact of orthostatic hypotension $(\mathrm{OH})$ on cognitive functions in patients with multiple system atrophy (MSA) followed over time.

Methods: Thirty-two MSA patients were enrolled and underwent a comprehensive neuropsychological battery; at baseline $\left(T_{0}\right) 15$ out of 32 patients presented $\mathrm{OH}$, assessed by means of orthostatic standing test. All patients underwent a follow-up $\left(T_{1}\right)$ evaluation 12 months after baseline. Thirteen out of 32 patients also underwent a second follow-up $\left(T_{2}\right)$ evaluation at 24 months. Changes over time on different neuropsychological tasks were compared between patients with and without $\mathrm{OH}$ by means of Mann-Whitney's U-test. Moreover, clinical categories of normal cognition, mild cognitive impairment, and dementia were determined, and changes at $T_{1}$ and $T_{2}$ in global cognitive status were compared between patients with and without $\mathrm{OH}$.

Results: At $\mathrm{T}_{0}$, patients with $\mathrm{OH}$ had better performance on words/non-words repetition task $(p=0.02)$ compared to patients without $\mathrm{OH}$. Compared to patients without $\mathrm{OH}$, patients with $\mathrm{OH}$ performed worse on semantic association task $(p<0.01)$ at $\mathrm{T}_{1}$ and on Stroop test-error effect $(p=0.04)$ at $T_{2}$. The percentage of patients with worsened cognitive status at $T_{1}$ was higher among patients with $\mathrm{OH}$ than among patients without $\mathrm{OH}$ (93 vs. $59 \%, p=0.03) . \mathrm{OH}(\beta=-4.67, p=0.01)$, education $(\beta=0.45, p=0.02)$, age $(\beta=0.19, p=0.03)$, and Montreal Cognitive Assessment battery (MOCA) score at $\mathrm{T}_{0}(\beta=-0.26, p=0.04)$ were significant predictors of global cognitive status worsening at $T_{1}$.

Discussion: We found that global cognitive status worsened at 1-year follow-up in 93\% of patients with $\mathrm{OH}$, and $\mathrm{OH}$, along with age, education, and MOCA score, predicted cognitive worsening over time. To clarify the relationship between $\mathrm{OH}$ and cognitive dysfunction in MSA, we suggest the use of clinical categories of normal cognition, mild cognitive impairment, and dementia in further longitudinal studies on MSA patients with and without $\mathrm{OH}$.

Keywords: $\alpha$-synucleinopathy, cognitive dysfunction, global cognitive status, multiple system atrophy, orthostatic hypotension 


\section{INTRODUCTION}

Multiple system atrophy (MSA) is a sporadic, progressive $\alpha$-synucleinopathy, clinically characterized by different combinations of rapidly progressive parkinsonism, cerebellar ataxia, autonomic failure, and corticospinal impairment. Specifically, the parkinsonian variant (MSA-P) is characterized by prominent akinetic-rigid parkinsonism and the cerebellar variant (MSA-C) by progressive ataxia $(1,2)$. In early disease stages, the diagnosis of MSA is mainly based on clinical features including significant autonomic dysfunction (3). One of the most important autonomic features of MSA is orthostatic hypotension $(\mathrm{OH})$, defined as a blood pressure (BP) drop of at least $20 / 10 \mathrm{~mm}$ $\mathrm{Hg}$ (systolic/diastolic) from supine to standing position (4). $\mathrm{OH}$ results from cardiovascular dysfunction caused by a complex interplay between central and peripheral autonomic dysregulation, cardiac noradrenergic sympathetic denervation, peripheral norepinephrine deficiency, and arterial baroreflex failure, finally leading to impaired arterial vasoconstriction and reduced compensatory cardiac output in response to hypotension (4). The prevalence of symptomatic $\mathrm{OH}$ is $55-80 \%$ in patients with MSA $(5,6)$. The clinical manifestations of $\mathrm{OH}$ are generally insidious and significantly associated with syncope, presyncope, accidental falls $(7,8)$, and increased mortality among elderly patients (9). $\mathrm{OH}$ is usually associated with cognitive symptoms; indeed, confusion is often described by affected patients $(7,8)$, but there is poor evidence about the relationship between $\mathrm{OH}$ and cognitive deficits in MSA patients (10).

The aim of this study is to investigate the impact of $\mathrm{OH}$ on cognitive functions in a sample of MSA patients evaluated longitudinally by means of a comprehensive neuropsychological assessment.

\section{METHODS}

\section{Patients}

Thirty-two patients with a diagnosis of probable MSA, according to current criteria (2), were enrolled at the Center for Neurodegenerative Diseases of the University of Salerno between November 2015 and April 2019. Brain magnetic resonance imaging (MRI) had been performed in all patients showing

Abbreviations: 5-RAWLT, Rey's auditory 15-word learning test; ADL, Basic Activities of Daily Life; AES, Apathy Evaluation Scale; BDI-II, Beck Depression Inventory; BJLO, Benton's Judgment of Line Orientation; BP, blood pressure; CDT, Clock Drawing test; DLB, dementia with Lewy body; DSM-5th, Statistical Diagnostic Manual of Psychiatry-5th Edition; F, female; IADL, Instrumental Activities of Daily Life; IQR, interquartile range; LEDD, total L-dopa equivalent daily dose; M, male; MCI, mild cognitive impairment; MDS, Movement Disorders Society; MMSE, Mini-Mental State Examination; MOCA, Montreal Cognitive Assessment battery; MSA, multiple system atrophy; MSA-C, multiple system atrophy with predominant cerebellar ataxia; MSA-D, multiple system atrophy with dementia; MSA-NC, multiple system atrophy with normal cognition; MSA$\mathrm{P}$, multiple system atrophy with predominant parkinsonism; N, number; NA, not applicable; $\mathrm{OH}$, orthostatic hypotension; $p$, $p$-value; PD, Parkinson disease; SAND, Screening for Aphasia in NeuroDegeneration; SCWT, Stroop Color-Word Test; SPSS, Statistical Package for Social Science; TMT-A, part A of Trail Making Test; $\mathrm{T}_{0}$, baseline; $\mathrm{T}_{1}$, follow up1; $\mathrm{T}_{2}$, follow up2; UMSARS, Unified Multiple System Atrophy Rating Scale. various combinations of putamen, middle cerebellar peduncle, pons, and cerebellum atrophy consistent with clinical diagnosis.

At baseline $\left(\mathrm{T}_{0}\right) 15$ of the 32 patients presented $\mathrm{OH}$, defined by a reduction of systolic BP of at least $20 \mathrm{~mm} \mathrm{Hg}$ or diastolic BP of $10 \mathrm{~mm} \mathrm{Hg}$ within $3 \mathrm{~min}$ of standing (11). Symptomatic $\mathrm{OH}$ was present in $93 \%$ of patients presenting $\mathrm{OH}$. Seventeen patients did not present $\mathrm{OH}$ at baseline and follow-up evaluations.

All patients underwent a follow-up $\left(\mathrm{T}_{1}\right)$ evaluation 12 months after baseline. Thirteen out of 32 patients also underwent a second follow-up $\left(\mathrm{T}_{2}\right)$ evaluation at 24 months. At $\mathrm{T}_{2}$ evaluation 4 patients were lost to follow-up, 8 were deceased, and 7 did not come back to the hospital due to Covid-19 restrictions. No patients received pharmacological treatment for $\mathrm{OH}$ during the study period.

The local Ethics Committee approved the study, and all patients signed informed consent.

\section{Clinical and Neuropsychological Assessments}

Demographic and clinical features are listed in Table $\mathbf{1 .}$

Cognitive abilities were assessed at baseline, $T_{1}$, and $T_{2}$ with the Montreal Cognitive Assessment (MOCA) (14), recall scores of the Rey's auditory verbal learning test (15-RAWLT-recall), recall and copy of Rey Osterrieth figure (ROCF), prose memory test, Trail Making Test-part A (TMT-A), Stroop Color-Word Test-error effect (SCWT), Clock Drawing test (CDT), verbal fluency test, constructional apraxia test, and Benton's Judgment of Line Orientation test (BJLO) (15), and sub-tests of Screening for Aphasia in NeuroDegeneration (SAND), such as naming, semantic association, and words and non-words repetition tasks (16). Depressive and apathetic symptoms were assessed by Beck Depression Inventory-II (BDI-II) and Apathy Evaluation Scale (AES) $(17,18)$.

Functional autonomy was evaluated with the Instrumental Activities of Daily Life (IADL) and with the Basic Activities of Daily Life (ADL). Where possible, tests were administered with random sequence.

\section{Statistical Analysis}

After normality distribution check, using the KolmogorovSmirnov test, the differences in demographic and cognitive variables between MSA patients with and without $\mathrm{OH}$ at $\mathrm{T}_{0}$ were computed by $\chi^{2}$ or the Mann-Whitney's $U$-test.

Changes in neuropsychological scores between $T_{1}$ and $T_{0}$ were calculated (Delta $=\mathrm{T}_{1}-\mathrm{T}_{0}$ ) and compared using MannWhitney's $U$-test in patients with and without $\mathrm{OH}$. Changes in neuropsychological scores between $\mathrm{T}_{2}$ and $\mathrm{T}_{0}$ were calculated (Delta $=\mathrm{T}_{2}-\mathrm{T}_{0}$ ) and compared using Mann-Whitney's $U$-test in patients with and without $\mathrm{OH}$. Significant results obtained from the exploratory analysis were then corrected for multiple comparisons, where necessary.

Patients were also divided according to cognitive status in MSA with normal cognition (MSA-NC), MSA with mild cognitive impairment (MCI)-single domain, MSA with MCImultiple domain, and MSA with dementia (MSA-D). Due to the lack of MSA-specific criteria for the diagnosis of MCI, it was diagnosed according to the Movement Disorders Society 
TABLE 1 | Clinical, demographic, and neuropsychological features in MSA patient with and without $\mathrm{OH}$ at baseline.

MSA with $\mathrm{OH}$ at $\mathrm{T}_{0}$

median (IQR)

( $N=15)$
MSA without $\mathrm{OH}$ at $\mathrm{T}_{0}$ median (IQR)

$(N=17)$

Clinical and demographic variables

Age

$$
\begin{gathered}
58(9) \\
11(11)
\end{gathered}
$$

Education

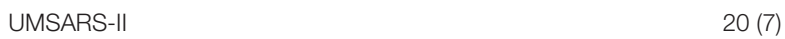

LEDD

$$
\begin{gathered}
62(10) \\
8(4) \\
5(2) \\
19(16) \\
304(199)
\end{gathered}
$$

\begin{tabular}{|c|c|c|c|}
\hline & $\begin{array}{c}\text { MSA with OH at } \\
\mathrm{T}_{0} \%(\mathbf{N}=15)\end{array}$ & $\begin{array}{c}\text { MSA without } \mathrm{OH} \text { at } \\
\mathrm{T}_{0} \%(\mathbf{N}=17)\end{array}$ & \\
\hline Gender (M \%) & $47 \%$ & $47 \%$ & 0.63 \\
\hline Supine hypertension (\%) & $18 \%$ & $0 \%$ & 0.22 \\
\hline Urinary incontinence (\%) & $80 \%$ & $88 \%$ & 0.65 \\
\hline \multicolumn{4}{|l|}{ Neuropsychological variables } \\
\hline \multicolumn{4}{|l|}{ General cognition } \\
\hline - MOCA & $21(8)$ & $21(7)$ & 0.07 \\
\hline \multicolumn{4}{|l|}{ Memory domain } \\
\hline - 15-RAWLT-recall ${ }^{\mathrm{a}}$ & $7(2)$ & $7(7)$ & 0.39 \\
\hline - Prose memorya & $12(4)$ & $10(4)$ & 0.66 \\
\hline - Recall of Rey Osterrieth figure ${ }^{a}$ & $10(10)$ & $15(14)$ & 0.84 \\
\hline \multicolumn{4}{|l|}{ Attention domain } \\
\hline - TMT-A & $81(48)$ & $64(88)$ & 0.32 \\
\hline - Stroop test-error interference ${ }^{a}$ & $2(3)$ & $12(18)$ & 0.04 \\
\hline \multicolumn{4}{|l|}{ Executive domain } \\
\hline - CDT ${ }^{\mathrm{a}}$ & $9(2)$ & $10(3)$ & 0.19 \\
\hline - Verbal fluency test ${ }^{a}$ & $21(17)$ & $18(23)$ & 0.47 \\
\hline - Copy of the Rey Osterrieth figure ${ }^{a}$ & $28(10)$ & $33(16)$ & 0.52 \\
\hline \multicolumn{4}{|l|}{ Visuospatial domain } \\
\hline - Constructional apraxia test ${ }^{a}$ & $11(5)$ & $11(5)$ & 0.48 \\
\hline - BJLOa & $18(8)$ & $19(11)$ & 0.55 \\
\hline \multicolumn{4}{|l|}{ Language domain } \\
\hline - Picture naming total ${ }^{a}$ & $12(4)$ & $13(2)$ & 0.98 \\
\hline - Words/no-words repetition-totala & $8(2)^{b}$ & $7(2)^{b}$ & 0.02 \\
\hline - Semantic association ${ }^{a}$ & $4(1)$ & $4(1)$ & 0.12 \\
\hline \multicolumn{4}{|l|}{ Mood domain } \\
\hline - BDI-II & $13(11)$ & $15(19)$ & 0.95 \\
\hline - AES & $33(12)$ & $36(15)$ & 0.20 \\
\hline \multicolumn{4}{|l|}{ Functional autonomy } \\
\hline$-A D L$ & $5(2)$ & $6(4)$ & 0.84 \\
\hline$-\mid A D L^{a}$ & $4(2)$ & $6(4)$ & 0.86 \\
\hline
\end{tabular}

$p$

Statistically significant differences are indicated in bold.

a Tests used to identify NC, MCl, and dementia $(12,13)$.

${ }^{b} \mathrm{MSA}$ with $\mathrm{OH}$ vs. MSA without $\mathrm{OH}$ (corrected $p \leq 0.03$ ).

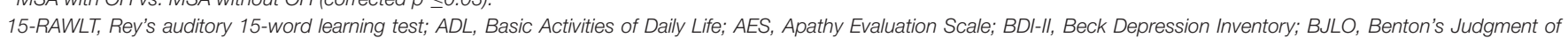

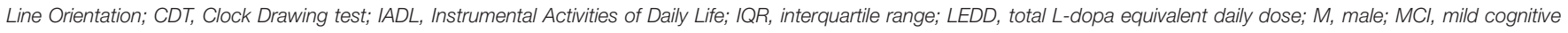

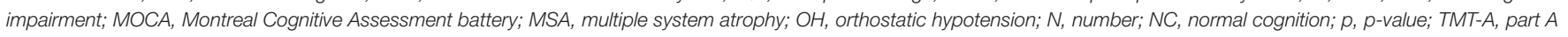
of Trail Making Test; To, baseline; UMSARS, Unified Multiple System Atrophy Rating Scale.

(MDS) criteria for MCI in Parkinson's disease (12). Dementia was diagnosed according to the Statistical Diagnostic Manual of Psychiatry-5th Edition (DSM-5). Subsequently, we divided the sample into two groups, according to worsening/not worsening of cognitive status at $T_{1}$ and $T_{2}$ as compared to $T_{0}$, and we compared the percentage of patients with and without $\mathrm{OH}$ in the 
two groups, by $\chi^{2}$ and Fisher test, where necessary. Specifically, cognitive status was defined as worsening if at least one more cognitive domain resulted altered at $\mathrm{T}_{1}$ or $\mathrm{T}_{2}$ as compared with $\mathrm{T}_{0}$ evaluation.

A logistic regression analysis with bootstrap method was performed with worsening or not-worsening as the dependent variable and $p<0.05$ deemed significant to evaluate a possible effect of $\mathrm{OH}$, age, education, gender, disease severity, disease duration, and MOCA score at baseline on cognitive status change at $T_{1}$. Due to the small sample size at $T_{2}$, no logistic regression was performed.

Finally, we analyzed the changes in neuropsychological scores between $\mathrm{T}_{1}$ and $\mathrm{T}_{0}$ (Delta $=\mathrm{T}_{1}-\mathrm{T}_{0}$ ) and between $\mathrm{T}_{2}$ and $\mathrm{T}_{0}$ (Delta $=\mathrm{T}_{2}-\mathrm{T}_{0}$ ) among MSA-P and MSA-C patients separately, comparing patients with and without $\mathrm{OH}$ by means of Mann-Whitney's $U$-test. Significant results obtained from the exploratory analysis were then corrected for multiple comparisons, where necessary.

Statistical analyses were performed by SPSS-20 (SPSS Inc., Chicago, IL).

\section{RESULTS}

At $\mathrm{T}_{0}$, patients with and without $\mathrm{OH}$ did not differ by age, education, disease duration, disease severity, total L-dopa equivalent daily dose (LEDD), or gender $(p>0.05)$ (Table 1$)$. At $\mathrm{T}_{0}$ patients with $\mathrm{OH}$ had better performance on words/nonwords repetition task than patients without $\mathrm{OH}(p=0.02)$ (Table 1).

At $\mathrm{T}_{1}$ patients with $\mathrm{OH}$ had worsened more than patients without $\mathrm{OH}$ on semantic association task $(p<0.01)$ (Table 2). At $\mathrm{T}_{2}$ patients with $\mathrm{OH}$ had worsened more than patients without $\mathrm{OH}$ on Stroop test-error effect $(p=0.04)$ (Table 3).

The percentage of patients with worsened cognitive status at $\mathrm{T}_{1}$ was higher among patients with $\mathrm{OH}$ than among patients without $\mathrm{OH}$ (93 vs. $59 \%, p=0.03$ ) (Figure 1).

Logistic regression analysis showed that $\mathrm{OH}(\beta=-4.67, p<$ $0.01)$, education $(\beta=0.45, p=0.02)$, age $(\beta=0.19, p=0.03)$, and MOCA score at $\mathrm{T}_{0}(\beta=-0.26, p=0.04)$ were significant predictors of global cognitive status worsening at $\mathrm{T}_{1}$, explaining $48 \%$ of the variance $\left(R^{2}=0.49\right)$, with $\mathrm{OH}$ accounting for $24 \%$ of variance. Gender $(\beta=-0.04, p=0.28)$, disease severity $(\beta=$ $-0.003, p=0.32)$, and disease duration $(\beta=-0.02, p=0.27)$ did not affect cognitive worsening at $\mathrm{T}_{1}$.

As for different phenotypes, 16 patients with MSA-C and 16 with MSA-P did not differ by age $(p=0.24)$, education $(p=0.99)$, disease duration $(p=0.49)$, Unified Multiple System Atrophy Rating Scale (UMSARS)-II $(p=0.12)$, or UMSARS-IV ( $p=$ 0.19). MSA-C patients with OH (9/16 MSA-C patients) worsened more than MSA-C patients without $\mathrm{OH}(7 / 16)$ at $\mathrm{T}_{1}$ on semantic association test $(p=0.02)$ and $\operatorname{AES}(p=0.04)$.

\section{DISCUSSION}

Cognitive disturbances in MSA range from mild single domain deficits to multiple domain impairment up to dementia in a
TABLE 2 | Changes in neuropsychological tests in MSA patients with and without $\mathrm{OH}$ at $\mathrm{T}_{1}$.

$\begin{array}{cc}\text { MSA with OH } & \text { MSA without OH } \\ \text { median (IQR) } & p \\ (N=15) & \text { median (IQR) } \\ (N=17)\end{array}$

Delta $T_{1}-T_{0}$

General cognition

- MOCA

$\begin{array}{ccc}-1(4) & -1(4) & 0.86 \\ -1(4) & 1(6) & 0.94 \\ 1(3) & 0(5) & 0.69 \\ -1(3) & -1(9) & 0.17\end{array}$

Memory domain

- 15-RAWLT-recall ${ }^{a}$

- Prose memory ${ }^{a}$

- Recall of Rey Osterrieth figure ${ }^{a}$

Attention domain

- TMT-A ${ }^{a}$

$0(20) \quad 8(34) \quad 0.60$

- Stroop test-error interference ${ }^{a}$

\section{$-1(3)$}

$-4(18)$

Executive domain

- CDT ${ }^{\mathrm{a}}$

- Verbal fluency test ${ }^{\mathrm{a}}$

$-1(4)$

$-1(4)$

0.49

- Copy of the Rey Osterrieth figure ${ }^{a}$

$-1(5)$

$-1(8)$

0.63

Visuospatial domain

- Constructional apraxia test ${ }^{a}$

- BJLOa

$-5(10)$

$-3(12)$

0.46

$-1(3)$

$-0(3)$

0.98

\section{Language domain}

- Picture Naming total ${ }^{a}$

- Words/no-words repetition-total ${ }^{a}$

- Semantic association ${ }^{a}$

\section{Mood domain}

- BDI-II

- AES

$0(8)$

$-3(4)$

0.12

Functional autonomy

- ADL

$-\operatorname{IADL}^{\mathrm{a}}$

Statistically significant differences are indicated in bold.

a Tests used to identify NC, MCl, and dementia $(16,19)$.

15-RAWLT, Rey's auditory 15-word learning test; ADL, Basic Activities of Daily Life; AES, Apathy Evaluation Scale; BDI-II, Beck Depression Inventory; BJLO, Benton's Judgment of Line Orientation; CDT, Clock Drawing test; IADL, Instrumental Activities of Daily Life; $I Q R$, interquartile range; $M C l$, mild cognitive impairment; MOCA, Montreal Cognitive Assessment battery; MSA, multiple system atrophy; $\mathrm{OH}$, orthostatic hypotension; $\mathrm{N}$, number; NC, normal cognition; $p, p$-value; TMT-A, part A of Trail Making Test; $T_{0}$, baseline; $T_{1}$, follow up 1.

minority of cases, but dementia is considered a non-supportive feature for the diagnosis of MSA (1). The severity of motor impairment may be a predictor of cognitive impairment in MSA (20-22), whereas the impact of $\mathrm{OH}$ on cognitive impairment has been poorly studied.

In our study, at baseline patients with $\mathrm{OH}$ differed from patients without $\mathrm{OH}$ only in a verbal repetition task, which indeed may be affected by speech disorders, motor programming, phonological encoding, and processing speed. At $\mathrm{T}_{1}$, we found that MSA patients with $\mathrm{OH}$ worsened on semantic memory and inhibition control skills more than patients without $\mathrm{OH}$. More interestingly, by using cognitive categories, such as normal cognition (NC), MCI, and dementia, we found that 
TABLE 3 | Changes in neuropsychological tests between MSA patients with and without $\mathrm{OH}$ at $\mathrm{T}_{2}$.

$\begin{array}{cc}\text { MSA with OH } & \text { MSA without OH } \\ \text { median (IQR) } & p \\ (N=7) & \text { median (IQR) } \\ (N=6)\end{array}$

\begin{tabular}{|c|c|c|c|}
\hline \multicolumn{4}{|l|}{ Delta $T_{2}-T_{0}$} \\
\hline \multicolumn{4}{|l|}{ General cognition } \\
\hline - MOCA & $-1(5)$ & $-4(6)$ & 0.66 \\
\hline \multicolumn{4}{|l|}{ Memory domain } \\
\hline - 15-RAWLT-recall ${ }^{\mathrm{a}}$ & $1(3)$ & $-3(7)$ & 0.16 \\
\hline - Prose memory ${ }^{a}$ & $-1(8)$ & $0(6)$ & 0.86 \\
\hline - Recall of Rey Osterrieth figure ${ }^{a}$ & $-1(3)$ & $-4(7)$ & 0.17 \\
\hline \multicolumn{4}{|l|}{ Attention domain } \\
\hline - TMT-A ${ }^{a}$ & $24(26)$ & $10(39)$ & 0.36 \\
\hline - Stroop test-error interference ${ }^{a}$ & $-1(4)$ & $-28(29)$ & 0.04 \\
\hline \multicolumn{4}{|l|}{ Executive domain } \\
\hline - CDT'a & $-2(9)$ & $-1(4)$ & 0.90 \\
\hline - Verbal fluency test ${ }^{a}$ & $-5(14)$ & $-3(8)$ & 0.93 \\
\hline - Copy of the Rey Osterrieth figure ${ }^{a}$ & $-7(10)$ & $-8(19)$ & 0.46 \\
\hline \multicolumn{4}{|l|}{ Visuospatial domain } \\
\hline - Constructional apraxia test ${ }^{a}$ & $-2(6)$ & $-3(3)$ & 0.52 \\
\hline - BJLOa & $-4(7)$ & $-4(2)$ & 0.92 \\
\hline \multicolumn{4}{|l|}{ Language domain } \\
\hline - Picture Naming total ${ }^{a}$ & $0(3)$ & $-1(3)$ & 0.81 \\
\hline - Words/no-words repetition-total ${ }^{\mathrm{a}}$ & $0(0)$ & $1(0)$ & 0.11 \\
\hline - Semantic association ${ }^{a}$ & $-1(2)$ & $0(0)$ & 0.32 \\
\hline \multicolumn{4}{|l|}{ Mood domain } \\
\hline - BDI-II & $-4(15)$ & $-5(6)$ & 0.46 \\
\hline - AES & $4(36)$ & $-5(45)$ & 0.48 \\
\hline \multicolumn{4}{|l|}{ Functional autonomy } \\
\hline - ADL & $-2(1)$ & $-2(2)$ & 0.62 \\
\hline$-\mid A D L^{a}$ & $-2(3)$ & $-1(3)$ & 0.64 \\
\hline
\end{tabular}

Statistically significant differences are indicated in bold.

a Tests used to identify NC, MCl, and dementia $(16,19)$.

15-RAWLT, Rey's auditory 15-word learning test; ADL, Basic Activities of Daily Life; AES, Apathy Evaluation Scale; BDI-II, Beck Depression Inventory; BJLO, Benton's Judgment of Line Orientation; CDT, Clock Drawing test; IADL, Instrumental Activities of Daily Life; IQR, interquartile range; $\mathrm{MCl}$, mild cognitive impairment; MOCA, Montreal Cognitive Assessment battery; MSA, multiple system atrophy; $\mathrm{OH}$, orthostatic hypotension; $\mathrm{N}$, number; NC, normal cognition; $p, p$-value; TMT-A, part A of Trail Making Test; $T_{0}$, baseline; $T_{2}$, follow up 2

almost all patients with $\mathrm{OH}$ worsened at 1-year follow-up on global cognitive status, suggesting that focusing on a single test is not very useful when assessing cognitive changes over time. Moreover, $\mathrm{OH}$ was an important predictor of cognitive worsening, together with education, age, and MOCA score, with $\mathrm{OH}$ accounting for half of the variance in the model. Our results are consistent with findings in patients with other $\alpha$ synucleinopathies, such as Parkinson disease (PD) and dementia with Lewy body (DLB), where a relationship between $\mathrm{OH}$ and cognitive impairment has been described, as well as a significant negative effect of $\mathrm{OH}$ on postural instability and survival in these diseases (10). For example, PD patients with $\mathrm{OH}$ showed worse performances in Mini-Mental State Examination (MMSE) (23), verbal memory test (24), attention, visuospatial working memory and delayed verbal recall (25), and digit vigilance and visual episodic memory (26) compared to PD patients without $\mathrm{OH}$. In a previous cross-sectional study (27) on 87 Korean drug-free patients with a diagnosis of early $\mathrm{PD}$, cognitive impairment and dementia were significantly more prevalent among patients with $\mathrm{OH}$ than those without.

In a longitudinal study of 80 cognitively intact PD patients with a mean age of 66 years and mean disease duration of 5.7 years, the risk of developing dementia over a mean follow-up of 4.4 years was strongly associated with the drop in orthostatic systolic BP, and subjects having a systolic drop higher than $10 \mathrm{~mm}$ $\mathrm{Hg}$ showed a 7-fold increased dementia risk (28). Moreover, in a study including patients with DLB, but also Alzheimer's disease (AD) and $\mathrm{AD}$ with a vascular component, the MMSE score was lower in patients with $\mathrm{OH}$ than patients without $\mathrm{OH}$ (29).

In MSA, the time between any initial symptom and combined motor and autonomic dysfunction is a predictor of poor prognosis and shorter survival (30). Ueda et al. (31) found that the mean $\mathrm{BP}$ and the change in the mean $\mathrm{BP}$ at $60^{\circ}$ tilt test were the only predictors of a MMSE score lower than 26 in MSA patients and suggested a careful observation of $\mathrm{OH}$ symptoms in order to detect cognitive dysfunction in patients with MSA. However, they did not analyze the differences in global cognitive performances between MSA with and without $\mathrm{OH}$. In another study, MSA patients with $\mathrm{OH}$ scored lower on the only neuropsychological task assessed, i.e., modified Wisconsin Card Sorting Test, as compared to patients without $\mathrm{OH}$, suggesting that $\mathrm{OH}$ was associated with frontal lobe dysfunction (32). On the other hand, Sambati et al. (33) found that 23 patients with MSA without cognitive impairment and 37 with cognitive impairment did not differ as for $\mathrm{OH}$. Although they recognized that $\mathrm{OH}$ can modify the cognitive system, they did not divide the sample based on $\mathrm{OH}$ but used $\mathrm{OH}$ as a dependent variable. However, as for the mechanism underlying the possible association between $\mathrm{OH}$ and cognitive impairment, Udow et al. (34) proposed two hypotheses: first, the co-occurrence of $\mathrm{OH}$ and cognitive impairment may be a manifestation of diffuse neuropathological involvement reflecting parallel neurodegeneration of regions responsible for cardiovascular autonomic control and cognition (19); second, $\mathrm{OH}$ on its own or together with supine hypertension may have a negative impact on cognition in $\alpha$-synucleinopathies, where the combination of cerebral hypoperfusion, with or without small vessel disease, may contribute to cognitive dysfunction (34).

In any case, the relationship between $\mathrm{OH}$ and cognitive impairment in PD is still controversial, since some authors have shown that, as reported for the elderly and patients with dementia, $\mathrm{PD}$ patients with $\mathrm{OH}$ were generally older than PD patients without $\mathrm{OH}$, suggesting that age rather than $\mathrm{OH}$ may contribute to a decline in cognitive function $(26,35,36)$. Similarly, O'Sullivan et al. (37) found no difference in time to develop cognitive impairment in MSA with early or late autonomic involvement.

On the other hand, our preliminary data may reflect more general findings in the middle-aged healthy population. In a review including 32 studies on $\mathrm{OH}$ and cognition in subjects with a mean or median age $\geq 65$ years, 18 studies reported an 


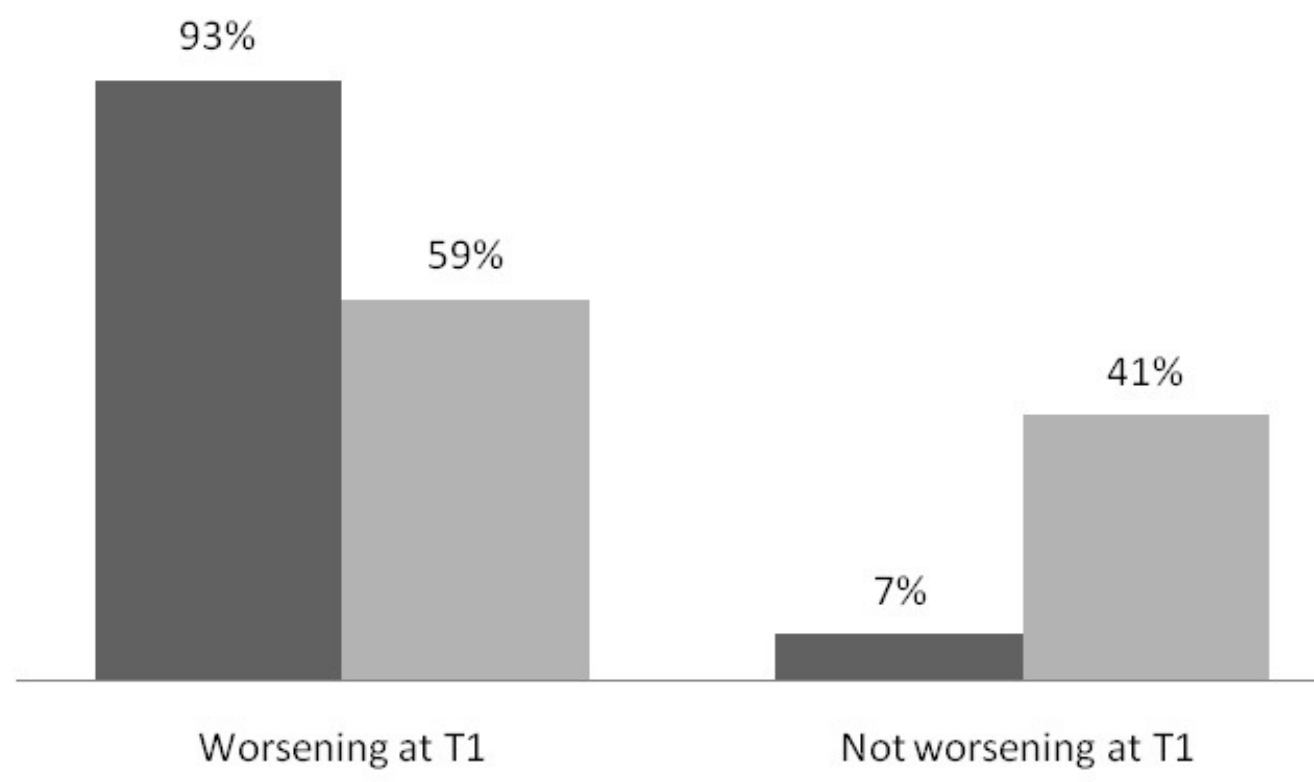

\section{MSA with $\mathrm{OH} \quad \mathrm{MSA}$ without $\mathrm{OH}$}

FIGURE 1 | Percentage of MSA patients with and without $\mathrm{OH}$ according to change in global cognitive status at $\mathrm{T}_{1}$. MSA, multiple system atrophy; OH, orthostatic hypotension; $T_{1}$, follow up 1.

association between $\mathrm{OH}$ and worse cognitive performance, and 14 reported no association. Interestingly, the studies using more than one cognitive task were more likely to find an association between $\mathrm{OH}$ and worse cognition, while the use of a single neuropsychological tool may underestimate this association (38). Furthermore, in a large longitudinal cohort of elderly subjects aged over 50 years, participants with $\mathrm{OH}$ showed a faster deterioration in executive and memory functions and presented a higher vascular burden as compared to participants without $\mathrm{OH}$ (39). However, it is still unclear whether the association between $\mathrm{OH}$ and poorer cognitive performance is causal, even in a general middle-aged population.

As for cognitive changes according to motor phenotypes, the finding of a worsening in semantic memory in MSA-C patients with $\mathrm{OH}$ can be ascribed to temporomesial cortex involvement (40), and, indeed, voxel-based morphometry MRI in MSA-C patients showed volume loss in the temporomesial cortex of both hemispheres as well as the left insular cortex as compared to healthy controls (41).

Regarding apathy, in literature there were few data about differences between MSA-P and MSA-C. Our preliminary data (42) showed that, independently from motor subtype, there was an increased prevalence of apathy over the course of MSA. A previous study (43) using the Neuropsychiatric Inventory (NPI) reported that there were no significant differences between MSA-P and MSA-C regarding neuropsychiatric symptoms, but that sleep disorders, apathy, and agitation/aggression were more severe in patients with MSA-C. However, Cao et al. (44) found that disease severity and MSA-C subtype are potential predictors of frontal lobe dysfunction. Therefore, patients with MSA-C might be more likely to have frontal lobe dysfunction than those with MSA-P, as reported also by Chang et al. (45). Additionally, the disruption of cerebellar-thalamo-cortical loops might also play a role in behavioral disorders $(46,47)$. This may account for the worsening of apathy in MSA-C as compared to MSA-P that was observed in our study.

We acknowledge that our study has some limitations, in particular, the short duration of the follow-up possibly affecting significant cognitive changes and the small sample at $\mathrm{T}_{2}$ evaluation. Moreover, our 2-year-follow-up data are preliminary due to the high percentage of patients lost at follow-up, which is justified by the fast progression of MSA.

In conclusion, further longitudinal studies on larger samples are necessary to confirm our preliminary data showing an association between $\mathrm{OH}$ and cognitive changes in MSA and to evaluate how chronic $\mathrm{OH}$ affects the long-term cognitive performance of patients with MSA.

\section{DATA AVAILABILITY STATEMENT}

The original contributions presented in the study are included in the article/supplementary material, further inquiries can be directed to the corresponding author/s.

\section{ETHICS STATEMENT}

The studies involving human participants were reviewed and approved by Local Ethics Committee- Campania Sud. The 
patients/participants provided their written informed consent to participate in this study.

\section{AUTHOR CONTRIBUTIONS}

SC: substantial contributions to the conception or design of the work, analysis, interpretation of data for the work, and drafting the work. IC, AC, SS, MR, VA, and LF: the acquisition of data for the work. MA, MP, RE, and $\mathrm{PB}$ : revising it critically for important intellectual content. MP: substantial

\section{REFERENCES}

1. Stankovic I, Krismer F, Jesic A, Antonini A, Benke T, Brown RG, et al., Cognitive impairment in multiple system atrophy: a position statement by the Neuropsychology Task Force of the MDS Multiple System Atrophy (MODIMSA) study group. Mov Disord. (2014) 29:85767. doi: $10.1002 / \mathrm{mds} .25880$

2. Gilman S, Wenning GK, Low PA, Brooks DJ, Mathias CJ, Trojanowski JQ, et al. Second consensus statement on the diagnosis of multiple system atrophy. Neurology. (2008) 71:670-6. doi: 10.1212/01.wnl.0000324625.00404.15

3. Köllensperger M, Geser F, Seppi K, Stampfer-Kountchev M, Sawires M, Scherfler C, et al. Red flags for multiple system atrophy. Mov Disord. (2008) 23:1093-9. doi: 10.1002/mds.21992

4. Jain S, Goldstein DS. Cardiovascular dysautonomia in Parkinson disease: from pathophysiology to pathogenesis. Neurobiol Dis. (2012) 46:57280. doi: 10.1016/j.nbd.2011.10.025

5. Colosimo C, Morgante L, Antonini A, Barone P, Avarello TP, Bottacchi E, et al. Non-motor symptoms in atypical and secondary parkinsonism: the PRIAMO study. J Neurol. (2010) 257:5-14. doi: 10.1007/s00415-009-5255-7

6. Ha AD, Brown $\mathrm{CH}$, York $\mathrm{MK}$, Jankovic J. The prevalenceof symptomatic orthostatic hypotension in patients with Parkinson's disease and atypical parkinsonism. Parkinsonism Relat Disord. (2011) 17:625-8. doi: 10.1016/j.parkreldis.2011.05.020

7. Gangavati A, Hajjar I, Quach L, Jones RN, Kiely DK, Gagnon P, et al., Hypertension, orthostatic hypotension, and the risk of falls in a communitydwelling elderly population: the maintenance of balance, independent living, intellect, and zest in the elderly of Boston study. J Am Geriatr Soc. (2011) 59:383-9. doi: 10.1111/j.1532-5415.2011.03317.x

8. Jodaitis L, Vaillant F, Snacken M, Boland B, Spinewine A, Dalleur O, et al., Orthostatic hypotension and associated conditions in geriatric inpatients. Acta Clin Belg. (2015) 70:251-8. doi: 10.1179/2295333715Y.00000 00006

9. Angelousi A, Girerd N, Benetos A, Frimat L, Gautier S, Weryha G, et al., Association between orthostatic hypotension and cardiovascular risk, cerebrovascular risk, cognitive decline and falls as well as overall mortality: a systematic review and meta-analysis. J Hypertens. (2014) 32:156271. doi: 10.1097/HJH.0000000000000235

10. Pilotto A, Romagnolo A, Tuazon JA, Vizcarra JA, Marsili L, Zibetti M, et al. Orthostatichypotension and REM sleepbehaviourdisorder: impact on clinicaloutcomesin $\alpha$-synucleinopathies. J Neuro lNeurosurg Psychiatry. (2019) 90:1257-63. doi: 10.1136/jnnp-2019-320846

11. Freeman $\mathrm{R}$, Wieling $\mathrm{W}$, Axelrod FB, Benditt DG, Benarroch $\mathrm{E}$, Biaggioni I, et al. Consensus statement on the definition of orthostatic hypotension, neurally mediated syncope and the postural tachycardia syndrome. Auton Neurosci. (2011) 161:46-8. doi: 10.1016/j.autneu.2011. 02.004

12. Litvan I, Goldman JG, Tröster AI, Schmand BA, Weintraub D, Petersen $\mathrm{RC}$, et al. Diagnostic criteria for mild cognitive impairment in Parkinson's disease: movement disorder society task force guidelines. Mov Disord. (2012) 27:349-56. doi: $10.1002 / \mathrm{mds} .24893$

13. APA, American Psychiatric Association (eds). Diagnostic and Statistical Manual of Mental Disorders. 5th ed. Arlington, VA: American PsychiatricAssociation (2013). contributions to the conception or design of the work, analysis, and interpretation of data for the work, revising it critically for important intellectual content, and final approval of the version to be published. All authors contributed to the article and approved the submitted version.

\section{FUNDING}

MP was supported by the Michael J Fox Foundation for Parkinson's research.
14. Santangelo G, Siciliano M, Pedone R, Vitale C, Falco F, Bisogno R, et al., Normative data for the Montreal Cognitive Assessment in an Italian population sample. Neurol Sci. (2015) 36:585-91. doi: 10.1007/s10072-014-1995-y

15. Barletta-Rodolfi C, Gasparini F, Ghidoni E. Kit del Neuropsicologo Italiano. Bologna: Società Italiana di Neuropsicologia (2011).

16. Catricalà E, Gobbi E, Battista P, Miozzo A, Polito C, Boschi V, et al., SAND: a screening for aphasia in neuroDegeneration. Development and normative data. Neurol Sci. (2017) 38:1469-83. doi: 10.1007/s10072-017-3001-y

17. Beck AT, Steer RA, Brown GK. Beck Depression Inventory. 2nd ed. San Antonio, TX: Psychological Corporation (1996). doi: 10.1037/t00742-000

18. Santangelo G, Barone P, Cuoco S, Raimo S, Pezzella D, Picillo M et al. Apathy in untreated, de novo patients with Parkinson's disease: validation study of Apathy Evaluation Scale. J Neurol. (2014) 261:231928. doi: 10.1007/s00415-014-7498-1

19. Idiaquez J, Roman GC. Autonomic dysfunction in neurodegenerative dementias. J Neurol Sci. (2011) 305:22-7. doi: 10.1016/j.jns.2011.02.033

20. Brown RG, Lacomblez L, Landwehrmeyer BG, Bak T, Uttner I, Dubois $B$, et al. Cognitive impairment in patients with multiple system atrophy and progressive supranuclear palsy. Brain. (2010) 133(Pt 8):2382-93. doi: 10.1093/brain/awq158

21. Kawamura K, Shimohata T, Nakayama H, Tomita M, Ozawa T, Nishizawa M. Factors influencing the cognitive function in patients with multiple system atrophy. Movem Disord. (2010) 25:2891-2. doi: 10.1002/mds.23260

22. Kim HJ, Jeon BS, Kim YE, Kim JY, Kim YK, Sohn CH, et al. Clinical and imaging characteristics of dementia in multiple system atrophy. Parkinsonism Relat Disord. (2013) 19:617-21. doi: 10.1016/j.parkreldis.2013.02.012

23. Hohler AD, Zuzuárregui JR, Katz DI, Depiero TJ, Hehl CL, Leonard A, et al. Differences in motor and cognitive function in patients with Parkinson's disease with and without orthostatic hypotension. Int J Neurosci. (2012) 122:233-6. doi: 10.1080/00207454.2012.642038

24. Bae HJ, Lim JH, Cheon SM. Orthostatic hypotension and cognitive impairment in de novo patients with Parkinson's disease. J Mov Disord. (2014) 7:102-4. doi: 10.14802/jmd.14016

25. Pilleri M, Facchini S, Gasparoli E, Biundo R, Bernardi L, Marchetti M et al. Cognitive and MRI correlates of orthostatic hypotension in Parkinson's disease. J Neurol. (2013) 260:253-9. doi: 10.1007/s00415-012-6627-y

26. Allcock LM, Kenny RA, Mosimann UP, Tordoff S, Wesnes KA, Hildreth AJ, et al. Orthostatic hypotension in Parkinson's disease: association with cognitive decline? Int J Geriatr Psychiatry. (2006) 21:778-83. doi: 10.1002/gps.1562

27. Kim JS, Oh YS, Lee KS, Kim YI, Yang DW, Goldstein DS. Association of cognitive dysfunction with neurocirculatory abnormalities in early Parkinson disease. Neurology. (2012) 79:1323-31. doi: 10.1212/WNL.0b013e31826clacd

28. Anang JB, Gagnon JF, Bertrand JA, Romenets SR, Latreille V, Panisset M, et al. Predictors of dementia in Parkinson disease: a prospective cohort study. Neurology. (2014) 83:1253-60. doi: 10.1212/WNL.0000000000000842

29. Bengtsson-Lindberg M, Larsson V, Minthon L, Wattmo C, Londos E. Lack of orthostatic symptoms in dementia patients with orthostatic hypotension. Clin Auton Res. (2015) 25:87-94. doi: 10.1007/s10286-0140244-z

30. Tada M, Onodera O, Tada M, Ozawa T, Piao YS, Kakita A, et al Early development of autonomic dysfunction may predict poor prognosis 
in patients with multiple system atrophy. Arch Neurol. (2007) 64:25660. doi: 10.1001/archneur.64.2.256

31. Ueda M, Nakamura T, Suzuki M, Imai E, Harada Y, Hara K, et al. Association of orthostatic blood pressure with the symptoms of orthostatic hypotension and cognitive impairment in patients with multiple system atrophy. J Clin Neurosci. (2020) 75:40-4. doi: 10.1016/j.jocn.2020. 03.040

32. Deguchi K, Takeuchi H, Sasaki I, Tsukaguchi M, Touge T, Nishioka M. Impaired novelty P3 potentials in multiple system atrophycorrelation with orthostatic hypotension. J Neurol Sci. (2001) 190:61-7. doi: 10.1016/S0022-510X(01)00588-3

33. Sambati L, Calandra-Buonaura G, Giannini G, Cani I, Provini F, Poda R, et al. Cognitive profile and its evolution in a cohort of multiple system atrophy patients. Front Neurol. (2020) 11:537360. doi: 10.3389/fneur.2020. 537360

34. Udow SJ, Robertson AD, MacIntosh BJ, Espay AJ, Rowe JB, Lang AE, et al. 'Under pressure': is there a link between orthostatic hypotension and cognitive impairment in $\alpha$-synucleinopathies? J Neurol Neurosurg Psychiatry. (2016) 87:1311-21. doi: 10.1136/jnnp-2016-314123

35. Allcock LM, Ullyart K, Kenny RA, Burn DJ. Frequency of orthostatic hypotension in a community based cohort of patients with Parkinson's disease. J Neurol Neurosurg Psychiatry. (2004) 75:1470-1. doi: 10.1136/jnnp.2003.029413

36. Gilman S, Low PA, Quinn N, Albanese A, Ben-Schlomo Y, Fowler CJ, et al. Consensus statement on the diagnosis of multiple system atrophy. J Neurol Sci. (1999) 163:94-8. doi: 10.1016/S0022-510X(98)00304-9

37. O'Sullivan SS, Massey LA, Williams DR, Silveira-Moriyama L, Kempster PA, Holton JL, et al., Clinical outcomes of progressive supranuclear palsy and multiple system atrophy. Brain. (2008) 131(Pt 5):1362-72. doi: 10.1093/brain/awn065

38. Iseli R, Nguyen VTV, Sharmin S, Reijnierse EM, Lim WK, Maier AB. Orthostatic hypotension and cognition in the elderly: a systematic review and a meta-analysis. Exp Gerontol. (2019) 120:40-9. doi: 10.1016/j.exger.2019.02.017

39. Zimmermann M, Wurster I, Lerche S, Roeben B, Machetanz G, Sünkel $\mathrm{U}$, et al., Orthostatic hypotension as a risk factor for longitudinal deterioration of cognitive function in the elderly. Eur J Neurol. (2020) 27:1607. doi: 10.1111/ene.14050

40. Duff MC, Covington NV, Hilverman C, Cohen NJ. Semantic memory and the hippocampus: revisiting, reaffirming, and extending the reach of their critical relationship. Front Hum Neurosci. (2020) 13:471. doi: 10.3389/fnhum.2019.00471

41. Brenneis C, Boesch SM, Egger KE, Seppi K, Scherfler C, Schocke M, et al. Cortical atrophy in the cerebellar variant of multiple system atrophy: a voxel-based morphometry study. Mov Disord. (2006)21:15965. doi: $10.1002 / \mathrm{mds} .20656$
42. Santangelo G, Cuoco S, Picillo M, Erro R, Squillante M, Volpe G, et al. Evolution of neuropsychological profile in motor subtypes of multiple system atrophy. Parkinsonism Relat Disord. (2020) 70:67-73. doi: 10.1016/j.parkreldis.2019.12.010

43. Siri C, Duerr S, Canesi M, Delazer M, Esselink R, Bloem BR, et al. A crosssectional multicenter study of cognitive and behavioural features in multiple system atrophy patients of the parkinsonian and cerebellar type. J Neural Transm. (2013) 120:613-8. doi: 10.1007/s00702-013-0997-x

44. Cao B, Zhao B, Wei QQ, Chen K, Yang J, Ou R, et al. The global cognition, frontal lobe dysfunction and behavior changes in chinese patients with multiple system atrophy. PLoS ONE. (2015) 10:e139773. doi: 10.1371/journal.pone.0139773

45. Chang CC, Chang YY, Chang WN, Lee YC, Wang YL, Lui CC, et al. Cognitive deficits in multiple system atrophy correlate with frontal atrophy and disease duration. Eur J Neurol. (2009) 16:114450. doi: 10.1111/j.1468-1331.2009.02661.x

46. Houck BD, Person AL. Cerebellar loops: a review of the nucleocortical pathway. Cerebellum. (2014) 13:378-85. doi: 10.1007/s12311-013-0543-2

47. Salmi J, Pallesen KJ, Neuvonen T, Brattico E, Korvenoja A, Salonen O, et al. Cognitive and motor loops of the human cerebro-cerebellar system. J Cogn Neurosci. (2010) 22:2663-76. doi: 10.1162/jocn.2009.21382

Conflict of Interest: Unrelated to this study, PB received consultancies as a member of the advisory board for Zambon, Lundbeck, UCB, Chiesi, Abbvie, and Acorda. RE received consultancies from Zambon and honoraria from TEVA. The other authors report no financial disclosures.

The remaining authors declare that the research was conducted in the absence of any commercial or financial relationships that could be construed as a potential conflict of interest.

Publisher's Note: All claims expressed in this article are solely those of the authors and do not necessarily represent those of their affiliated organizations, or those of the publisher, the editors and the reviewers. Any product that may be evaluated in this article, or claim that may be made by its manufacturer, is not guaranteed or endorsed by the publisher.

Copyright (C) 2021 Cuoco, Carotenuto, Cappiello, Scannapieco, Russillo, Andreozzi, Forino, Amboni, Picillo, Erro, Barone and Pellecchia. This is an open-access article distributed under the terms of the Creative Commons Attribution License (CC BY). The use, distribution or reproduction in other forums is permitted, provided the original author(s) and the copyright owner(s) are credited and that the original publication in this journal is cited, in accordance with accepted academic practice. No use, distribution or reproduction is permitted which does not comply with these terms. 